WRPS-50235

Revision 0

\title{
Pilot-Scale Field Validation of the Long Electrode Electrical Resistivity Tomography Method
}

Prepared for the U.S. Department of Energy Assistant Secretary for Environmental Management

Contractor for the U.S. Department of Energy

Office of River Protection under Contract DE-AC27-08RV14800

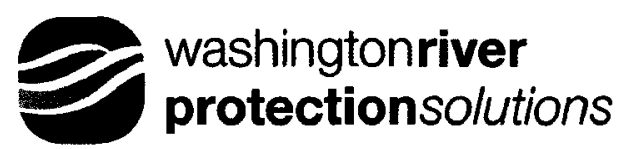

P.O. Box 850

Richland, Washington 99352 
WRPS-50235

Revision 0

\section{Pilot-Scale Field Validation of the Long Electrode Electrical Resistivity Tomography Method}

D. F. Rucker

HydroGEOPHYSICS, Inc. Tucson, AZ USA

M. H. Loke

Geotomo Software. Penang, Malaysia
N. Crook

HydroGEOPHYSICS, Inc. Richland, WA USA

D. R. Glaser

Washington River Protection Solutions

Date Published

July 2011

To Be Presented at

EAGE

Published in

Geophysical Prospecting

Prepared for the U.S. Department of Energy

Assistant Secretary for Environmental Management

Contractor for the U.S. Department of Energy

Office of River Protection under Contract DE-AC27-08RV14800

\section{washingtonriver}

\section{protectionsolutions}

P.O. Box 850

Richland, Washington

Copyright License

By acceptance of this article, the publisher and/or recipient acknowledges the U.S. Government's right to retain a nonexclusive, royalty-free license in and to any copyright covering this paper.

D. D. Raudal Release Approval

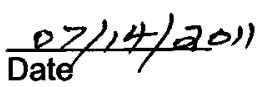

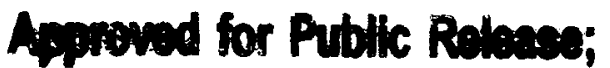

Further Dissemination Unilimited 
LEGAL DISCLAMER

This report was prepared as an account of work sponsored by an agency of the United States Government. Neither the United States Government nor any agency thereof, nor any of their employees, nor any of their contractors, subcontractors or their employees, makes any warranty, express or implied, or assumes any legal liability or responsibility for the accuracy, completeness, or any third party's use or the results of such use of any information, apparatus, product, or process disclosed, or represents that its use would not infringe privately owned rights. Reference herein to any specific commercial product, process, or service by trade name, trademark, manufacturer, or otherwise, does not necessarily constitute or imply its endorsement, recommendation, or favoring by the United States Government or any agency thereof or its contractors or subcontractors. The views and opinions of authors expressed herein do not necessarily state or reflect those of the United States Government or any agency thereof.

This report has been reproduced from the best available copy. Available in paper copy. 
Pilot-Scale Field Validation of the Long Electrode Electrical Resistivity Tomography Method

Dale F. Rucker ${ }^{1}$, Nigel Crook ${ }^{2}$, Danney Glaser ${ }^{3}$, and Meng H. Loke ${ }^{4}$

${ }^{1}$ hydroGEOPHYSICS, Inc. Tucson, AZ USA drucker@hgiworld.com; druck8240@gmail.com

${ }^{2}$ hydroGEOPHYSICS, Inc. Richland, WA USA

${ }^{3}$ Washing ton River Protection Solutions, LLC. Richland, WA USA

${ }^{4}$ Geotomo Software. Penang, Malaysia

\begin{abstract}
Field validation for the long electrode electrical resistivity tomography (LE-ERT) method was attempted in order to demonstrate the performance of the technique in imaging a simple buried target. The experiment was an approximately $1 / 17$ scale mock-up of a region encompassing a buried nuclear waste tank on the Hanford site. The target of focus was constructed by manually forming a simulated plume within the vadose zone using a tank waste simulant. The LE-ERT results were compared to ERT using conventional point electrodes on the surface and buried within the survey domain. Using a pole-pole array, both point and long electrode imaging techniques identified the lateral extents of the pre-formed plume with reasonable fidelity, but the LE-ERT was handicapped in reconstructing the vertical boundaries. The pole-dipole and dipole-dipole arrays were also tested with the LE-ERT method and were shown to have the least favorable target properties, including the position of the reconstructed plume relative to the known plume and the intensity of false positive targets. The poor performance of the pole-dipole and dipole-dipole arrays was attributed to an inexhaustive and non-optimal coverage of data at key electrodes, as well as an increased noise for electrode combinations with high geometric factors. However, when comparing the model resolution matrix among the different acquisition strategies, the pole-dipole and dipole-dipole arrays using long electrodes were shown to have significantly higher average and maximum values than any pole-pole array. The model resolution describes how well the inversion model resolves the subsurface. Given the model resolution performance of the pole-dipole and dipole-dipole arrays, it may be worth investing in tools to understand the optimum subset of randomly distributed electrode pairs to produce maximum performance from the inversion model.
\end{abstract}

\title{
Introduction
}

The use of electrical resistivity in understanding the fate of contaminants in the subsurface is becoming common due to the robustness of the sensor (or electrode) and relatively low cost of the method (Meju and Montague, 1995; Damasceno et al., 2009), when compared with more direct means of characterization and monitoring. Examples of mapping contaminant plumes with electrical resistivity include Kemna et al. (2002), Hayley et al. (2009), and Monego et al. (2010). The method's success for imaging the existence and possibly the bounds of a plume relies primarily on a heightened contrast in electrical properties between the contaminated porewater and the host matrix (de Lima et al., 1995; Adepelumi et al., 2006). As described, the resistivity method acts as a target recognition tool, requiring that sufficient background be captured to ensure that the full scope of the target's footprint is represented in the electrical resistivity images. Conversion of simple target recognition results to a meaningful understanding of hydrogeological or geochemical parameters requires additional knowledge of the subsurface conditions, likely obtained from drilling or other direct sampling methods.

Industrialized areas pose a challenge to the traditional paradigm for electrical resistivity characterization. Although these areas are a major source of contamination, liabilities such as limited access for electrode placement and the degree of near surface metallic infrastructure (e.g., wells, tanks, 
for validation, such as complementary geophysical methods (e.g., Deiana et al., 2007; Looms et al., 2008), have also been presented.

A more complete knowledge of the subsurface for field validation can only be achieved through destructive post-survey analyses of the soil or by burying a target composed of an amended soil of known concentration. In this work, we applied the amended soil method for field validation of the LEERT method to gain insight into its ability to reconstruct a known static target. Although the target properties were well known, an exhaustive measure of the surrounding soil was not conducted. Instead, a few representative samples were taken of the excavated soil to make generalizations about the background conditions. The arrangement of the long electrodes was designed to replicate a 1/17 scaled mock-up of a Hanford tank farm. The target was constructed by hand to simulate a saline contaminant plume using two soils of known properties and dimensions. The electrical resistivity measurement campaign included a combination of surface, long, and a few buried point electrodes, similar to the survey designs described in Rucker et al. (2011b). Image reconstruction from the distributed point electrodes on the surface and buried in the survey domain was considered as a standard for which to make comparisons with LE-ERT. We investigated the fidelity of target reconstruction from three different array types (pole-pole, pole-dipole, and dipole-dipole) for LE-ERT surveying and the model resolution of each array. The work contained here-in will attempt to demonstrate the strength of the LE-ERT method as an alternative to using traditional point electrodes, when the latter is not an option for use.

\section{Experimental Site Description}

A pilot-scale field validation of the LE-ERT method was conducted to demonstrate the resolution capabilities for targets at the Hanford site in central Washington. The Hanford site is home to a large number of underground storage tanks, grouped into tank farms, some of which may have leaked a substantial volume of contamination to the vadose zone. Additionally, direct disposal of waste occurred to the ground in nearby unlined trenches, sunken vaults (referred to as cribs), ponds, reverse wells, etc. Understanding the degree to which the soil and groundwater have been impacted is difficult because the site is highly industrialized, limiting both direct (drilling and sampling) and indirect (geophysical characterization) methodologies.

The pilot-scale field validation was conducted within the top two meters of soil in an open field west of the Pacific Northwest National Laboratory, approximately $30 \mathrm{~km}$ south of Hanford's tank locations. Soil conditions at the experimental site are very similar to the storage tank region, due to the large cataclysmic flooding and associated sediment deposition from the Missoula Flood (see coverage maps in Baker and Bunker, 1985 and Bjornstad et al., 2001). Figure 1A shows the experimental site location as well as the location of the Hanford tank farms distributed in 200 East and 200 West. In general, the near surface soil consists of reworked Hanford formation, a predominantly unconsolidated group of sediments that cover a wide range of grain size, from sand to silt, and sorting, (Bjornstad and Lanigan, 2007). Since the end of the Pleistocene, winds have deposited dune sands and loess sediments (Reidel et al., 1992) in the region. The dunes are stabilized by anchoring vegetation, including grasses, forbs, and sage brush. At the experimental site, only a few grasses were present. 

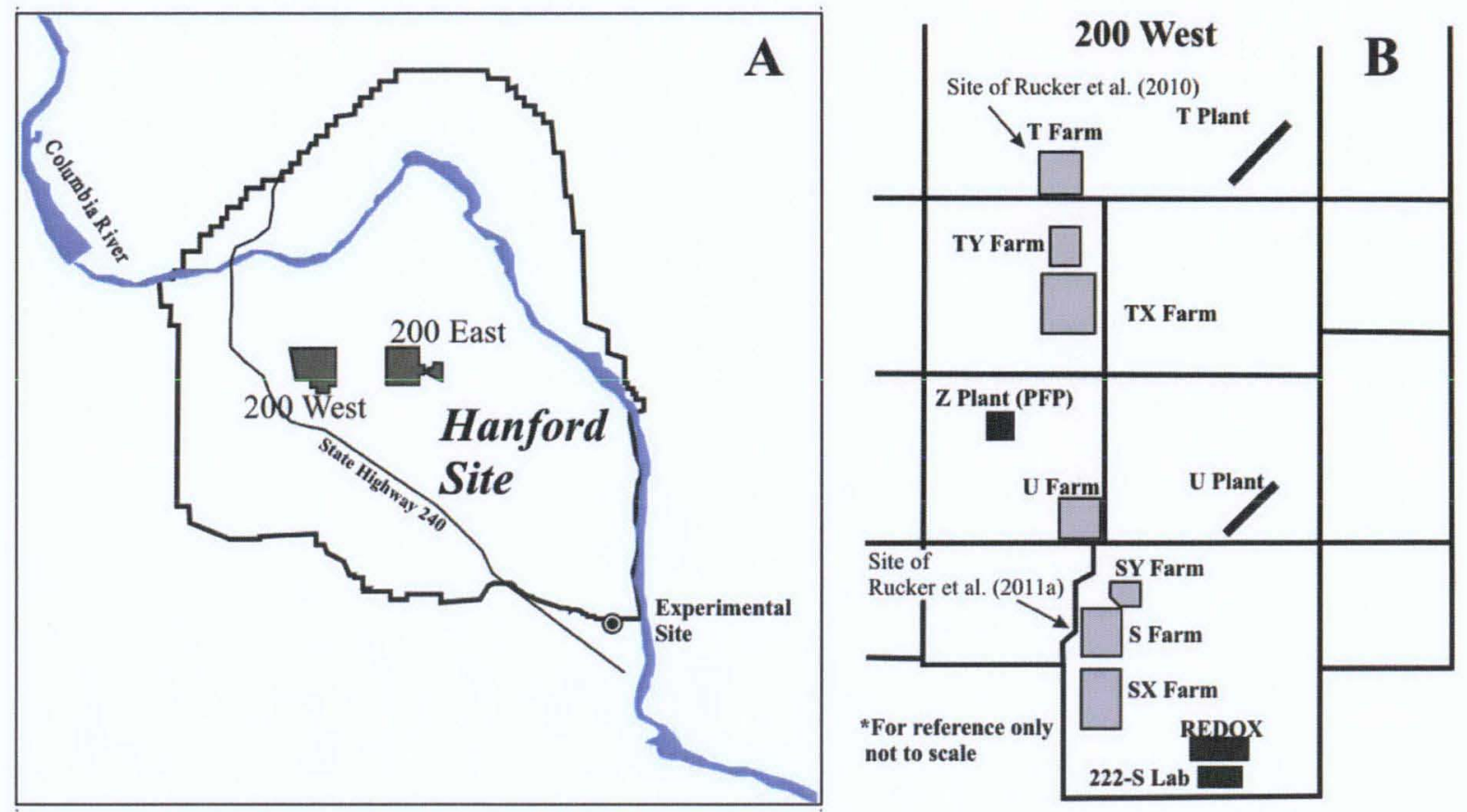

Figure 1. A) Site Location for the LE-ERT field validation relative to the tank farms located in 200 East and 200 West. B) Location of tanks farms within 200 West area and published studies where the LE-ERT method has been conducted.

On a broader scale, the Hanford tank farms are situated within the Hanford formation, which can be over $100 \mathrm{~m}$ thick in some locations. The tanks themselves were installed below ground and backfilled with disturbed Hanford formation soil. Outside the local backfilled regions, the formation is divided into three units from $\mathrm{H} 1$ to $\mathrm{H} 3$. The upper $\mathrm{H} 1$ unit is composed of predominantly loose, sandy gravel to gravelly sand, with minor beds of sand to silty sand. Coarser beds may contain boulder-sized materials and occasional thin, discontinuous lenses of fine sand and silt occur sporadically (Bergeron et al., 2010). The $\mathrm{H} 2$ unit is composed of mostly cross-bedded sand and gravelly sand, with some sand beds capped by thin layers of silty sand to sandy silt. The H3 unit is composed of open framework gravel and poorly sorted sandy gravel to silty sandy gravel (Bergeron et al., 2010). In the 200 West area, the Hanford formation is underlain by the Cold Creek unit, a carbonate-rich and cemented paleosol. The Cold Creek unit is almost absent in the 200 East area. Below the Cold Creek, the sediments deposited for the Ringold formation represents the early stages of the Columbia River. Generally the water table is located in the Ringold formation. Rucker et al. (2011a) shows a cross section through the $\mathrm{S}$ tank farm, the location of which is shown in Figure 1B.

\section{Experimental Design}

The resistivity experiment was designed to mimic a Hanford tank farm setting, where a hypothetical tank leak created a saline plume in the vadose zone. The standard single-shelled tank is $23 \mathrm{~m}$ in diameter and approximately $9 \mathrm{~m}$ tall from base to dome. The sediment cover from the apex of the dome to ground surface is about $2.5 \mathrm{~m}$. The tanks were constructed of concrete with a carbon steel liner and a thick concrete-asphalt external layer to protect the tanks from corrosion. An electrically resistive round plastic tub was used to replicate the tank. The dimensions of the tub were $1.8 \mathrm{~m}$ 
diameter and $0.45 \mathrm{~m}$ high; the tub was buried where the top was even with the ground surface. Figure $2 \mathrm{~A}$ and $2 \mathrm{~B}$ shows the tub location.

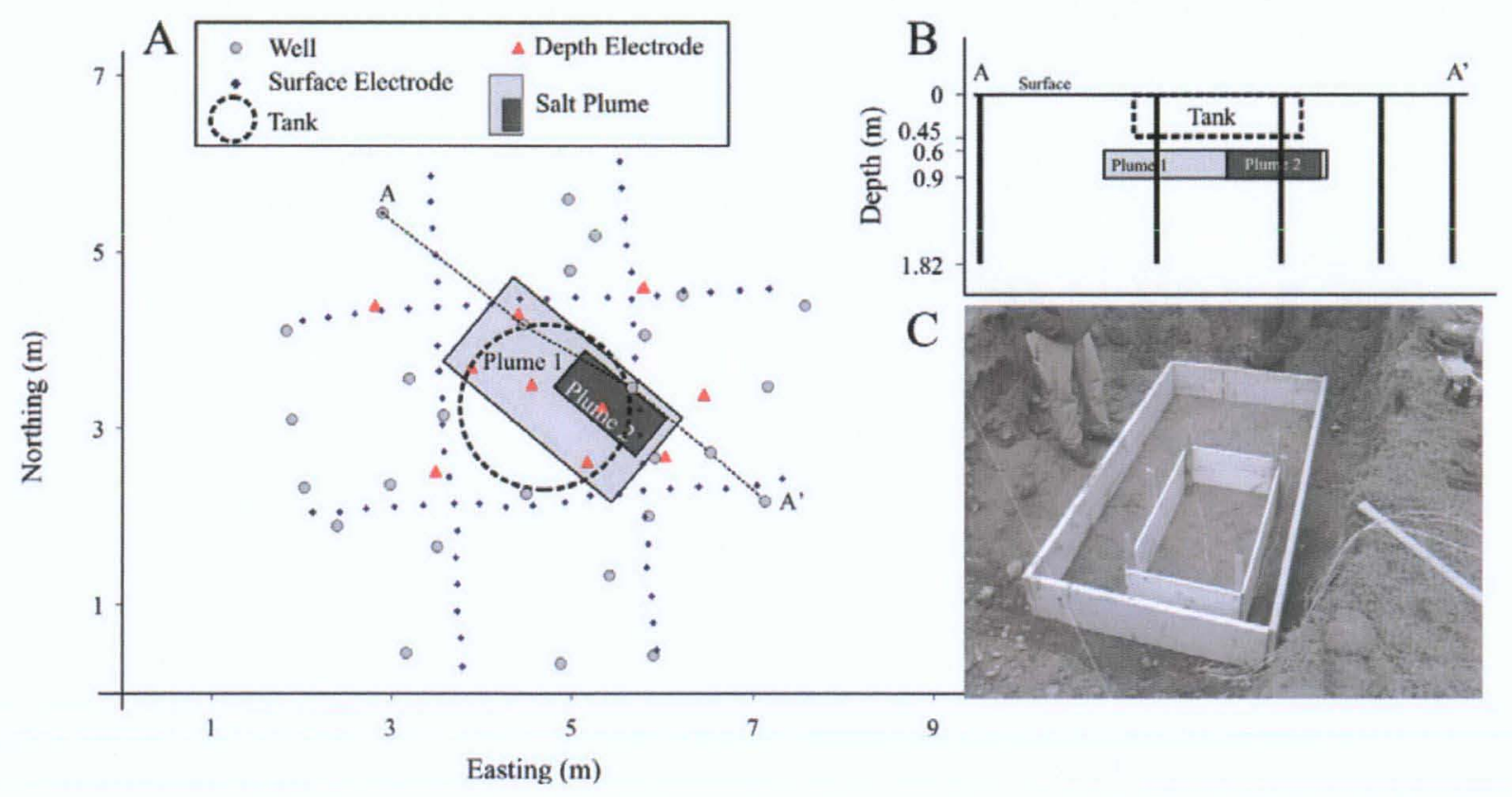

Figure 2. A) Plan view map of the validation experiment, showing the different point and long electrodes, tank, and simulated plumes. B) Profile view through A-A'. C) Photo of forms used to place amended soil for LE-ERT target identification.

Surrounding each tank is a series of steel-cased monitoring wells that are typically completed above the water table (which is approximately $70-100 \mathrm{~m}$ below ground surface, depending on location). An entire Hanford tank farm could have more than 60 monitoring wells. A number of groundwater wells, used for water sampling and analysis, are also positioned outside the tank farms. Together, the set of vadose and groundwater wells form a broad distribution of coverage for LE-ERT imaging. For the pilot-scale experiment, a series of 27 steel wells were placed around the tub in an arrangement that was similar to tank B105 in the B tank farm (Knepp, 2002). The wells were replicated by a solid core stainless steel rod, $0.019 \mathrm{~m}$ diameter and $1.8 \mathrm{~m}$ long, and were driven into the ground by an electric percussion hammer. Figure $2 \mathrm{~A}$ and $2 \mathrm{~B}$ shows the layout of the wells relative to the tank. In addition, 70 surface electrodes and 10 buried electrodes, both acting as point source electrodes, were installed as part of the experiment to provide a basis for comparison of the LE-ERT results. The base separation of the surface electrodes was $0.3 \mathrm{~m}$. The depth electrodes were placed at the top of the amended soil target $(0.6 \mathrm{~m})$, at the base of the target $(0.9 \mathrm{~m})$, and significantly below the target $(1.5 \mathrm{~m})$. A few of the depth electrodes were nested at a couple of positions.

The simulated plume was constructed by removing the soil, amending it, and repacking into forms. Figure $2 \mathrm{C}$ shows a photo of the dug out with temporary wooden forms used for establishing plume dimensions. The hand-packing option allowed control over the shape, size, and properties, providing a fixed and known target to image. Figure $2 \mathrm{~A}$ and $2 \mathrm{~B}$ shows the position of the plume with dimensions of $2.43 \mathrm{~m}$ by $1.21 \mathrm{~m}$, and $0.3 \mathrm{~m}$ in height. The plume is stationed at the edge of the tank, rotated to the northwest, and laying flat. The plume was constructed by mixing a solution of sodium thiosulfate 
pentahydrate $\left(\mathrm{Na}_{2} \mathrm{~S}_{2} \mathrm{O}_{3} \bullet 5 \mathrm{H}_{2} \mathrm{O}\right)$ with the soil in a gas-powered cement mixer. This salt was chosen due to its use on the Hanford Site for many other experiments involving resistivity imaging of plumes. Two concentrations, 20,000 and $40,000 \mathrm{mg} / \mathrm{L}$, were mixed to produce a low resistivity outer plume (Plume 1) and a very low resistivity inner plume (Plume 2). The electrical resistivity of the solutions was approximately 0.5 and $0.25 \mathrm{ohm}-\mathrm{m}$. The amount of solution added to the soil equated to an increase of 3 percent by weight for the outer plume and 5 percent for the inner plume. The addition of a low volume of solution was meant to prevent gravity drainage of the plume away from the source and avoid diffusional processes that would likely smear the plume edges within the time scale of the survey. The final resistivity values of the soil representing the inner and out plume were roughly 190 and $320 \mathrm{ohm}$ $\mathrm{m}$, respectively. This is in contrast to an average background of approximately $1320 \mathrm{ohm}-\mathrm{m}$ (taken from ten measurements ranging from 580 to $2840 \mathrm{ohm}-\mathrm{m}$ to a depth of $1 \mathrm{~m}$ ). The contrast between background and target in this study closely resembled the values found in recent resistivity studies on site. For example, Rucker et al. (2009) showed results from a resistivity survey conducted an the BC Cribs and Trenches Area on the Hanford site, with contaminated soil resistivity values ranging from 10 to $250 \mathrm{ohm}-\mathrm{m}$ and background values in excess of $1000 \mathrm{ohm}-\mathrm{m}$.

\section{Point Electrode Validation}

To conduct the resistivity measurements, a SuperSting $\mathrm{R} 8$ with two 56-channel switchboxes (manufactured by AGI in Austin, TX) were used to connect with all 112 electrodes at once. The electrodes were connected to the resistivity acquisition system using 16-gauge multi-stranded copper wire, which required two intermediate 56-channel patch panels to make the actual connection of the wires to the switchboxes. The patch panels were constructed so that a dedicated banana plug could be linked to each individual channel on the switchbox. To minimize noise a $3.6 \mathrm{~s}$ sampling window was used. Each measurement was stacked with three windows and data rejection was set to two percent error. Full reciprocals for data acquired with the pole-pole array were obtained to gain an understanding of the measurement error. The reciprocal measurements were collected with a forward set and reverse set; the infinite poles being switched for each set. Reciprocal data from the pole-dipole and dipole-dipole arrays with the LE-ERT method were not acquired.

Figures $3 \mathrm{~A}$ through $3 \mathrm{C}$ show a series of plots that represent data statistics for the point electrode data, including the surface and buried electrodes. For the 80 available point electrodes, there are a total of 3160 possible non-reciprocal measurement pairs. Figure $3 A$ shows the transfer resistance versus electrode separation distance for 2995 data values from the forward set, after removal of low quality data. The data from closer electrode spacing displays the highest variability and the remaining data appear to fall off linearly in semi-log space. Figure 3B shows the apparent resistivity data versus electrode separation, where transfer resistance was converted to apparent resistivity $\left(\rho_{a}\right)$ using:

$\rho_{a}=2 \pi r \frac{V}{l}$

where $r$ is the separation between the transmitter and receiver electrodes and $V / I$ is the transfer resistance, calculated as measured voltage divided by input current. The data from closer electrode spacings appears to have lower resistivity than the larger spacings, likely indicating that the near surface is slightly more conductive. Finally, Figure $3 \mathrm{C}$ shows the reciprocal error (RE) for the measurements calculated as: 
$R E=\frac{(V / I)_{f}-(V / I)_{r}}{(V / I)_{f}} \cdot 100$

where subscript $f$ and $r$ represent the forward and reverse acquisition data for the same measurement pair. The difference between the pair of measurements should ideally be zero and any deviation from zero may give a measure of the quality of the data (Chambers et al., 2010). Assessing errors due to high contact resistances, random instrument errors, and sporadic errors due to background noise is easily conducted using the reciprocal error (Slater et al., 2000).

After addressing the reverse data set to remove low quality data and aligning with the forward set, 2820 values remain for each of the forward and reverse data sets. Of these, 2750 from each set were shown to be within 5\%, which are shown in Figure 3C. The data with the closer electrode spacings appear to have the higher reciprocal errors. In addition, the forward data set are, on average, lower than the reverse data set. It is unclear what could be causing the bias.

Data processing and inversion for the point electrode data was conducted with RES3DINVx64, version 3.04.26 (Geotomo Software, Malaysia). Inverse modeling is conducted through a linearized least squares optimization, with the goal of finding the best fit of modeled apparent resistivity commensurate with the measured apparent resistivity. Given the flat topography of the site, we chose to use the computationally fast finite-difference method to solve the partial differential equation for the voltage distribution (Dey and Morrison, 1979):

$\frac{\partial}{\partial x}\left(\frac{1}{\rho} \frac{\partial V}{\partial x}\right)+\frac{\partial}{\partial y}\left(\frac{1}{\rho} \frac{\partial V}{\partial y}\right)+\frac{\partial}{\partial z}\left(\frac{1}{\rho} \frac{\partial V}{\partial z}\right)+I=0$

Additionally, we used the L2-norm smoothness constraint for the inverse modeling, described by (Loke et al., 2010):

$\left(J_{i}^{T} J_{i}+C\right) \Delta r_{i}=J_{i}^{T} g_{i}-C r_{i-1}$

where $g$ is the misfit vector containing the difference between the measured and modeled apparent resistivity data, $J$ is the Jacobian matrix of partial derivatives, $C$ contains the various constraints used for stabilizing the inverse procedure, $\Delta r_{i}$ is the change in model parameters (i.e., electrical resistivity) for the $i^{\text {th }}$ iteration, and $r_{i}$ is the model parameters for the previous iteration. Further descriptions of resistivity inversion can be found in Park and Van (1991) and Li and Oldenburg (1994). 

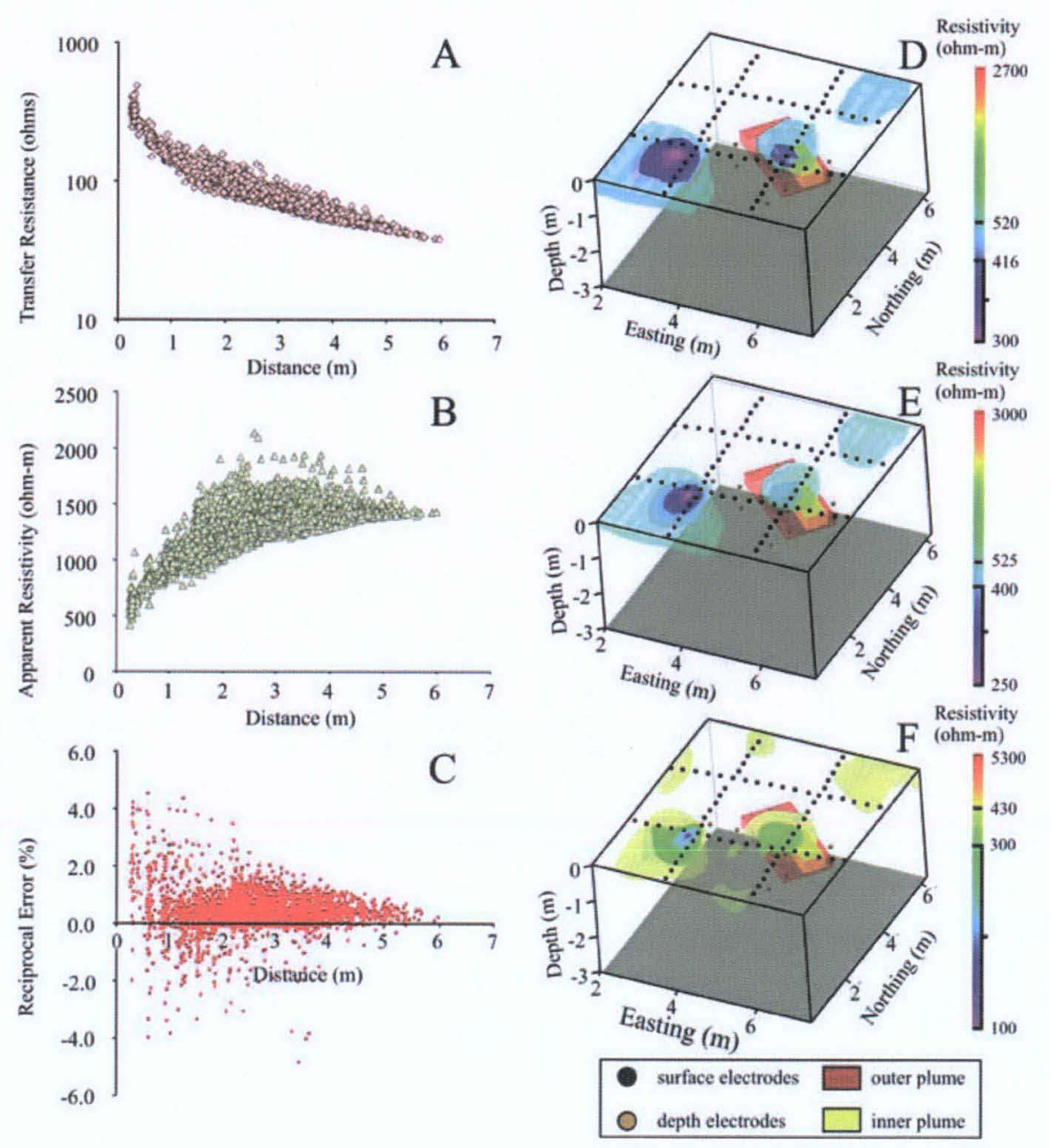

Figure 3. Data and inversion results from the point electrodes. A) Transfer resistance (ohms) vs. electrode separation distance B) Apparent resistivity (ohm-m) vs. electrode separation distance. C) Reciprocal error vs. electrode separation distance, showing a slight underestimation in the forward data compared to the reverse data set. D) Inverse model results for a square model grid of $0.6 \mathrm{~m}$ showing two isopleths of $520 \mathrm{ohm}-\mathrm{m}$ (translucent) and $416 \mathrm{ohm}-\mathrm{m}$ (opaque). E) Inverse model results for a square model grid of $0.30 \mathrm{~m}$ showing two isopleths of $525 \mathrm{ohm}-\mathrm{m}$ (translucent) and $400 \mathrm{ohm}-\mathrm{m}$ (opaque). F) Inverse model results for a square model grid of $0.15 \mathrm{~m}$ showing two isopleths of $430 \mathrm{ohm}$ $\mathrm{m}$ (translucent) and $300 \mathrm{ohm}-\mathrm{m}$ (opaque).

For the point electrode data several inverse model cell sizes were tested to gain an understanding of resolution versus target fidelity. Layering of the models was consistent throughout all of the tests, developed from a telescoping sequence with a top layer thickness of $0.1 \mathrm{~m}$ and bottom layer thickness of $0.5 \mathrm{~m}$. Three tests were run that included square cells of $0.15 \mathrm{~m}, 0.3 \mathrm{~m}$, and $0.6 \mathrm{~m}$, statistics for the models are listed in Table 1.

Table 1. Statistics for the point electrode inversions

\begin{tabular}{|l|l|l|l|l|}
\hline Cell Size $(\mathrm{m})$ & $\begin{array}{l}\text { Rows, columns, } \\
\text { layers }\end{array}$ & Total cell count & $\begin{array}{l}\text { Total data } \\
\text { count }\end{array}$ & $\begin{array}{l}\text { Figure } \\
\text { number }\end{array}$ \\
\hline
\end{tabular}




\begin{tabular}{|l|l|l|l|l|}
\hline 0.15 & $34 \times 41 \times 14$ & 19,516 & 2750 & $3 \mathrm{~F}$ \\
\hline 0.3 & $19 \times 21 \times 14$ & 5,586 & 2750 & $3 \mathrm{E}$ \\
\hline 0.6 & $10 \times 11 \times 14$ & 1,540 & 2750 & $3 \mathrm{D}$ \\
\hline
\end{tabular}

The results of the inversion, showing the three dimensional representation of targets within the domain, are presented in Figure 3D-3F for inverse model cell sizes of $0.6,0.3$, and $0.15 \mathrm{~m}$, respectively. The resistivity data are presented at two isopleths, with the lower resistivity isopleth as an opaque body and the larger resistivity isopleth as a transparent body. The value of the resistivity presented for each isopleth was chosen to encompass roughly the same volume of material for all models and the exact values are shown on the color scales to the right of the figure. The smaller body equated to approximately $0.85 \mathrm{~m}^{3}$ while the larger body equated to approximately $4.7 \mathrm{~m}^{3}$. In all three instances, a target is observed at the location of the pre-constructed plumes, shown in the figures for reference. For all cases, both the smaller and larger isopleth appear offset towards the western edge of the preconstructed plumes. Additionally, there are other targets within the domain that are consistent among the models, notably the very low resistivity at the surface on the southwest side of the domain and a marginally low resistivity body on the northeast corner. It is unknown what is causing these features to appear in the results.

Regarding target fidelity, the smallest cell size of $0.15 \mathrm{~m}$ (Figure 3F) appears to replicate the target edges, especially the bottom and top edge, better than the other two larger cell sizes. The drawback is that potentially more false targets appear within the domain, as shown in the upper layers of the model. Since it would be an impracticality to attempt to sample all of the soil measured during initial design, it is possible that the smaller targets identified in Figure $3 \mathrm{~F}$ are actual subsurface features. This is supported by the observation that the lowest values of apparent resistivity, shown at close electrode spacings in Figure $3 \mathrm{~B}$, are observed in the very near surface of Figure 3F. However, the sizes of the small targets are on par with the cell size of the $0.3 \mathrm{~m}$ simulation and should have been imaged in Figure $3 E$ if they were true targets.

\section{Model Resolution}

Formally, the model resolution $(R)$ is a matrix that is computed from the Jacobian and other model constraints and describes how well the inversion model resolves the subsurface (Day-Lewis et al., 2005):

$R=\left(J_{i}^{T} J_{i}+C\right)^{-1} J^{T} J$

$R$ may be viewed as a filter that blurs the true values of the subsurface resistivities(Stummer et al., 2004):

$r^{\text {est }}=R r^{\text {true }}$

where $r^{\text {est }}$ is the vector of the estimated model parameters obtained by applying Eq. (4) and $r^{\text {true }}$ is the true subsurface resistivity. The values within $R$ will range from zero to one, a perfectly resolved model is one in which the diagonals are equal to a value of one. Stummer et al. (2004) stated that values greater than 0.05 were considered acceptable, based on their analysis for $2 \mathrm{D}$ resistivity profile inversions. For 3D work, such as presented here, we will accept a lower resolution based on the lower spatial electrode density. From a computational standpoint, calculating the resolution matrix is expensive, and Loke et al. (2010) and Wilkinson et al. (2006) presented ways to help reduce the number of operations. In this work we used the method of Loke et al. (2010) as implemented in RES3DINVx64. 
Alumbaugh and Newman (2000) used the model resolution to understand the effects of key assumptions from electromagnetic inversion models. Stummer et al. (2004), Wilkinson et al. (2006), and Loke et al. (2010) used the model resolution to derive the best combination of surface measurements to obtain improved representation of subsurface targets for 2D problems. Applying a hybrid of these approaches, we investigated the consequence of typical decisions made for inverting resistivity data to resolve a target, including model parameters (inverse model cell size) and electrode density. Figure 4 shows a series of model resolution results, plotted in log scale, for a group of four models. Figure $4 \mathrm{~A}$ through $4 \mathrm{C}$ shows the model resolution for the original electrode layout presented in Figure 2 with an inverse model cell size of $0.3 \mathrm{~m}$ (see Figure $3 \mathrm{E}$ for resistivity results). The three figures are plotted for the first model layer (at a depth $0.05 \mathrm{~m}$ ), through the center of the amended soil plume (at $0.8 \mathrm{~m}$ ), and below the plume (at $1.6 \mathrm{~m}$ ). At the surface, the results show that the model is best resolved along the lines of electrodes; the maximum resolution is only 0.024 . A solid line is placed at the 0.01 resolution contour interval for reference. For the layer through the center of the plume, the highest resolution is coincident with the target, which may be an affect of both depth electrode locations and target properties; the maximum resolution for this layer is 0.076 . The lowest layer on Figure $4 \mathrm{C}$ shows the highest resolution values coincident with the four point electrodes at that depth.

For the remaining models, we increased the inverse model cell size to twice that of the electrode spacing to $0.6 \mathrm{~m}$ (shown in Figures 4D-F), reduced the electrode coverage to every other electrode along each line while maintaining a $0.3 \mathrm{~m}$ inverse model cell (Figures 4G-4I), and eliminated the depth electrodes but kept the original surface electrodes and cell size of $0.3 \mathrm{~m}$ (Figures $4 \mathrm{~J}-4 \mathrm{~L}$ ). Although intuitive, the best results were obtained by increasing the model cell size to $0.6 \mathrm{~m}$, with the maximum resolution value of 0.35 observed for the layer though the plume. The worst resolution can be seen in the model without depth electrodes. Surprisingly, however, reducing the surface electrodes had little effect on the overall resolution. When designing field surveys with a finite number of channels on the resistivity meter, these results suggest that surface electrodes can be sacrificed to ensure adequate electrode coverage deeper in the subsurface.

\section{Long Electrode Validation}

Pole-Pole Acquisition

Rucker et al. (2010; 2011a) demonstrated case studies for characterization and monitoring of plumes with the LE-ERT method in a tank farm at Hanford. The background, theory, and parameterization for conducting the models were also presented (ibid.). For this analysis, we applied the same technique for the 27 wells distributed around the pilot-scale test area, namely using the L2 norm formulation of the inverse procedure. 


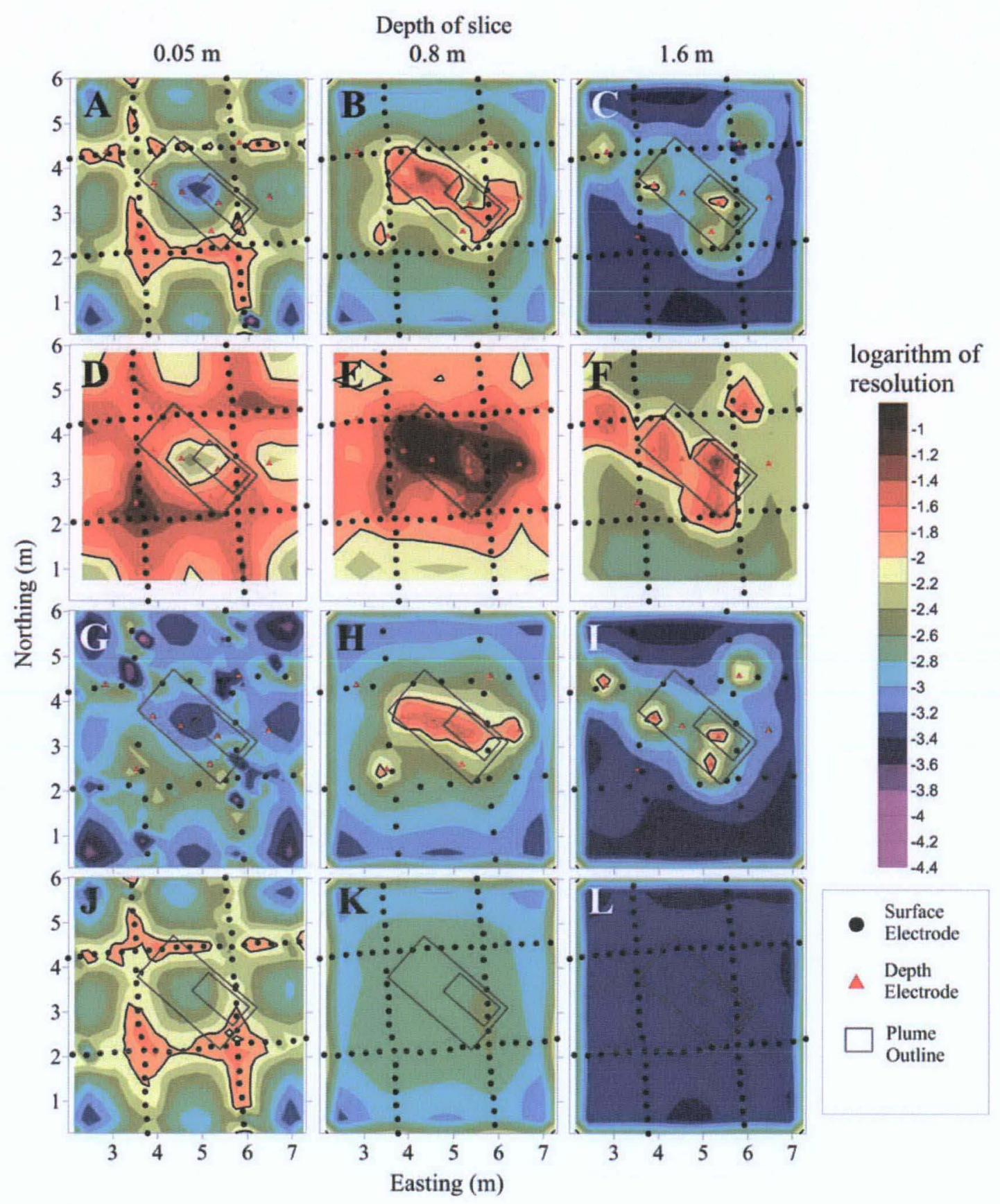

Figure 4. Model resolution for point electrodes. A) Slice at $0.05 \mathrm{~m}$ with electrode separation of $0.3 \mathrm{~m}$ and inverse model cell of $0.3 \mathrm{~m}$. B) Slice at $0.8 \mathrm{~m}$ with electrode separation of $0.3 \mathrm{~m}$ and inverse model cell of $0.3 \mathrm{~m}$. C) Slice at $1.6 \mathrm{~m}$ with electrode separation of $0.3 \mathrm{~m}$ and inverse model cell of $0.3 \mathrm{~m}$. D through F) Equivalent layers for increased cell size of $0.6 \mathrm{~m}$. G through I) Reduced electrode density to $0.6 \mathrm{~m}$ separation and model cell of $0.3 \mathrm{~m}$. J through $\mathrm{L}$ ) Equivalent of $A$ through $\mathrm{C}$ but without depth electrodes. 
The electrical data acquired on the wells using the pole-pole array are shown in Figure 5, similar to the plots presented in Figure 3. The total number of combinations with 27 wells using the pole-pole array is 351 , only 5 measurements were eliminated from the dataset. The transfer resistance shows a power function relationship with distance, with an exponent of -0.71 . The point electrode data showed a similar relationship with an exponent of -0.69 . The close spaced data for the apparent resistivity data in Figure 5B show a lowered resistivity than the more distant data, but this likely has more to do with the incorrect conversion of transfer resistance to apparent resistivity than the properties of the earth. Rucker et al. (2010) showed how to convert transfer resistance measurements using long electrode transmitters and point electrode receivers to apparent resistivity by incorporating aspects of the well length. No known conversion exists for the long electrode to long electrode combinations and Eq. (1) was used instead. The reciprocal error in Figure $5 \mathrm{C}$ shows a lower degree of error than the point electrode data, withno spatial bias. However, there still appears to be a slight underestimation by the forward data acquisition set.
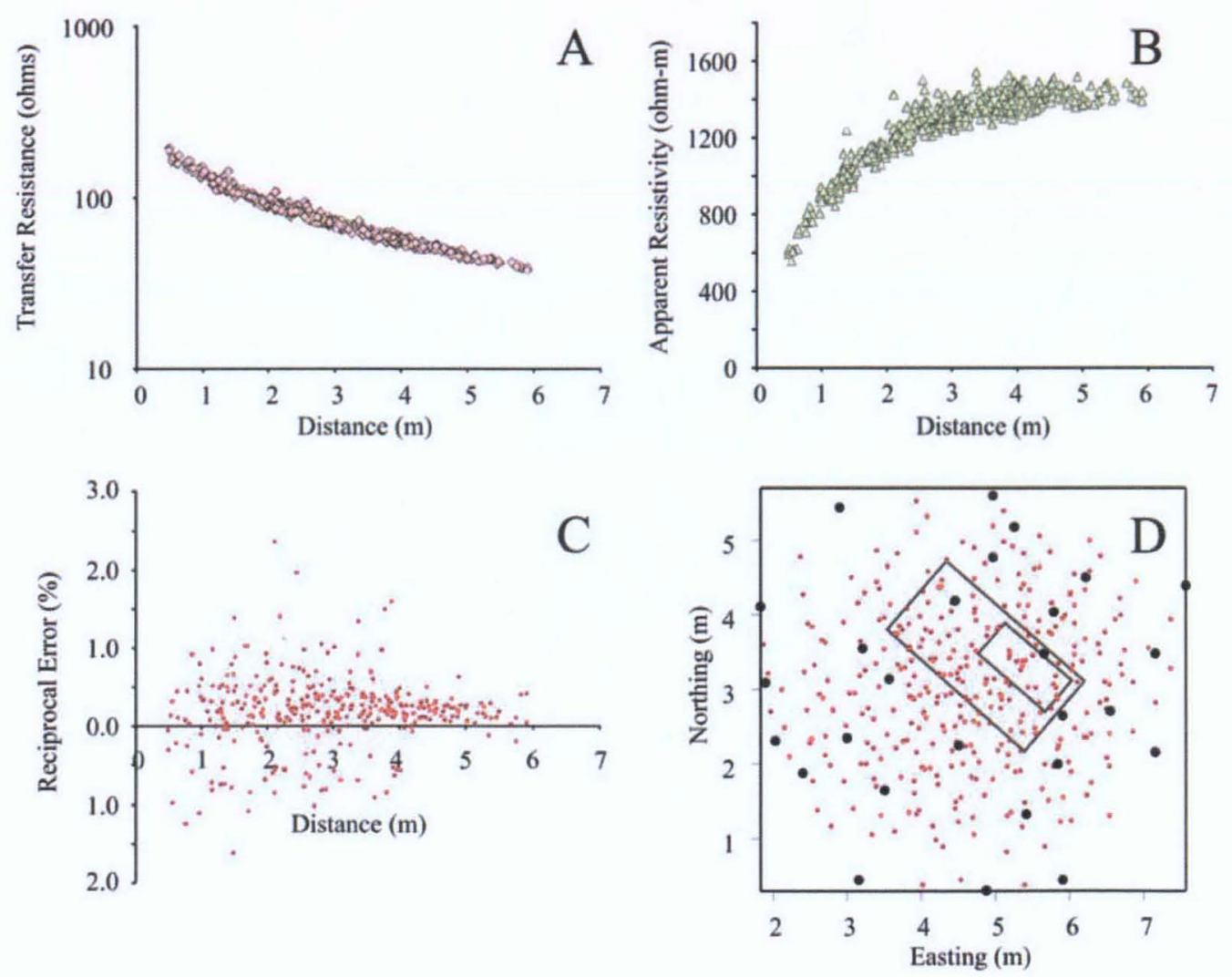

Figure 5. Electrical data statistics from the long electrodes using the pole-pole array. A) Transfer resistance (ohms) vs. electrode separation distance B) Apparent resistivity (ohm-m) vs. electrode separation distance. C) Reciprocal error electrode separation, showing a slight underestimation in the forward data compared to the reverse data set. D) Point cloud of data density.

Figure 5D shows a point cloud of data from the long electrodes, created by taking the midpoint between each transmitter and receiver electrode combination, similar to a pseudosection for 2D profiles. The 
plot shows a high concentration of data points near the center and towards the plume. Although a qualitative measure, it will be a valuable comparison for the pole-dipole and dipole-dipole point cloud, presented below, to ensure that the latter two arrays had sufficient coverage of the subsurface for comparison.

The results of inverting the pole-pole LE-ERT data are presented in Figure 6 . We investigated two cell sizes: $0.3 \mathrm{~m}$ (Figure $6 \mathrm{~A}, \mathrm{C}$, and $\mathrm{E}$ ) and $0.6 \mathrm{~m}$ (Figure 6B, D, and F). The resistivity plots in Figures $6 \mathrm{~A}$ and $6 \mathrm{~B}$ represent the first layer of the model at $0.1 \mathrm{~m}$. Rucker et al. (2010) demonstrated that the targets tend to create the largest footprint at the surface of the model, likely due to the maximum current density at the surface elevation. The figures show that both models replicated the amended soil target with relatively good accuracy, given the significantly lower number of electrodes and data compared to the point electrode models. In addition, the LE-ERT results display the northeast and southwest surficial targets imaged in the point electrode models.

The model resolution of the two inverse model cell sizes are presented for the surface (Figures $6 \mathrm{C}$ and 6D) and for a layer through the center of the plume at a depth of $0.8 \mathrm{~m}$ (Figures $6 \mathrm{E}$ and $6 \mathrm{~F}$ ). For direct comparison with the point electrode models, the same color scale was used, with a solid line contour through the 0.01 value. Similar to the results of the point electrode results, the larger cell size tended to produce a better resolved model. However, the LE-ERT models have both a lower average and maximum resolution than the point electrode models (Figures $4 \mathrm{~A}$ through $4 \mathrm{~F}$ ) for the same cell size. The maximum LE-ERT model resolution for the $0.3 \mathrm{~m}$ cell size at the surface was 0.008 , compared to a value of 0.024 for the equivalent point electrode model; the maximum LE-ERT model resolution for the $0.6 \mathrm{~m}$ cell size was 0.038 versus a value of 0.093 for the point electrode model. The lower model resolution values for the long electrode model were likely due to the significant difference in the number of electrodes.

\section{Pole-Dipole and Dipole-Dipole Acquisition}

Similar to the pole-pole (PP) array acquisition with long electrodes, data from both the pole-dipole (PD) and dipole-dipole (DD) arrays were acquired for the pilot-scale validation test. The difference, however, is in the exhaustive combination set obtained with the PP array versus a smaller subset of data acquired with DD and PD arrays. At the time of acquisition in 2007, there were no means to create a complete data command file for randomly distributed electrodes for 3D analysis using the Super Sting R8 resistivity meter. The manual creation of the command file meant that not all pairs were viable, such as those with an extremely large geometric factors or a negative transfer resistance, and that the best combinations were not necessarily included in the command file. Of the 9950 PD and 7189 DD measurements, 3995 (for PD) and 4546 (for DD) were retained for inverse modeling based on previously outlined data reduction practices. To illustrate there was no spatial bias in the data acquisition and the region surrounding the soil plume had symmetric coverage, a point cloud was created for each array. Figures $7 \mathrm{~A}$ and $7 \mathrm{~B}$ show how the point clouds were created for the PD and DD arrays, respectively. Figures $7 C$ and $7 D$ show that the results of the point cloud, like the PP array, produce ample coverage from all of the wells around the target. The last two subplots in Figure 7 show the transfer resistance versus the geometric factor for PD and DD arrays. The geometric factor (GF) was calculated as (Telford et al., 1990): 

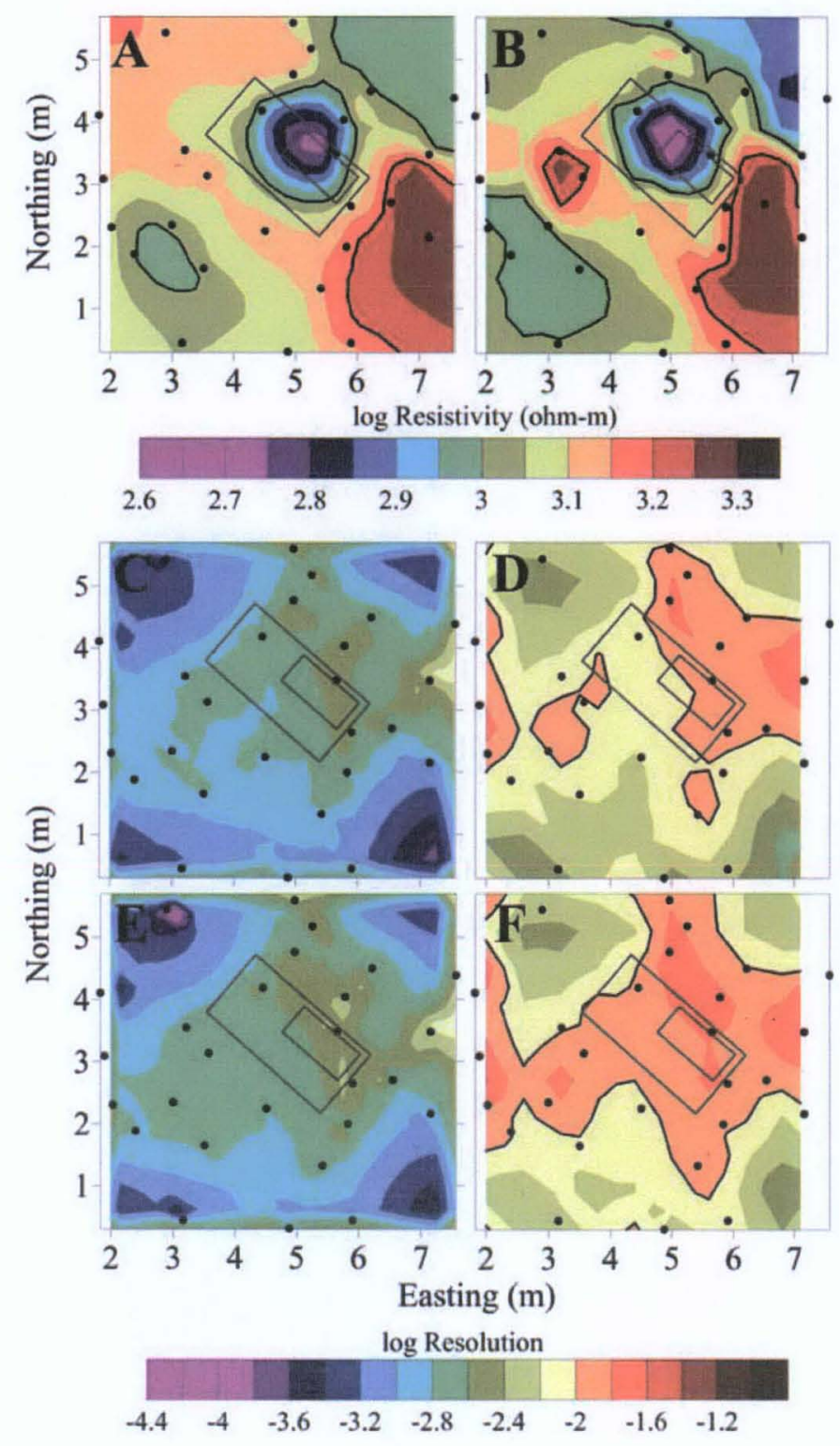

Figure 6. Inversion results for the LE-ERT for the pole-pole array. Feature legend for the contour plots are the same as Figure 4. A) Resistivity of the top layer of a model with cell size of $0.3 \mathrm{~m}$. B) Resistivity of the top layer of a model with cell size of $0.6 \mathrm{~m}$. C) Resolution of the top layer for a cell size of $0.3 \mathrm{~m}$. D) Resolution of the top layer for a cell size of $0.6 \mathrm{~m}$. E) Resolution of the layer through the plume $(0.8 \mathrm{~m})$ for a cell size of $0.3 \mathrm{~m}$. F) Resolution of the layer through the plume $(0.8 \mathrm{~m})$ for a cell size of $0.6 \mathrm{~m}$.

$G F=\left(\left|\frac{1}{\overline{A M}}\right|-\left|\frac{1}{\overline{A N}}\right|-\left|\frac{1}{\overline{B M}}\right|+\left|\frac{1}{\overline{B N}}\right|\right)^{-1}$

where $\mathrm{A}, \mathrm{B}, \mathrm{M}$, and $\mathrm{N}$ are the locations of the transmitter and receiver pairs of electrodes. For the PP array, the geometric factor reduces to the distance between transmitter and receiver electrodes 
(Figures $3 \mathrm{~A}$ and $5 \mathrm{~A}$ ). Both PD and DD arrays of Figure $7 \mathrm{E}$ and $7 \mathrm{~F}$ show a linear relationship of transfer resistance versus geometric factor on a log-log plot, and the exponents for the power fit are -0.72 (for PD) and -0.75 (for DD). These are similar to exponents observed with the PP array on both long and point electrodes. It is interesting to note the larger data point spread at higher geometric factors, likely attributed to the lower signal to noise ratio for both arrays compared to the PP array.

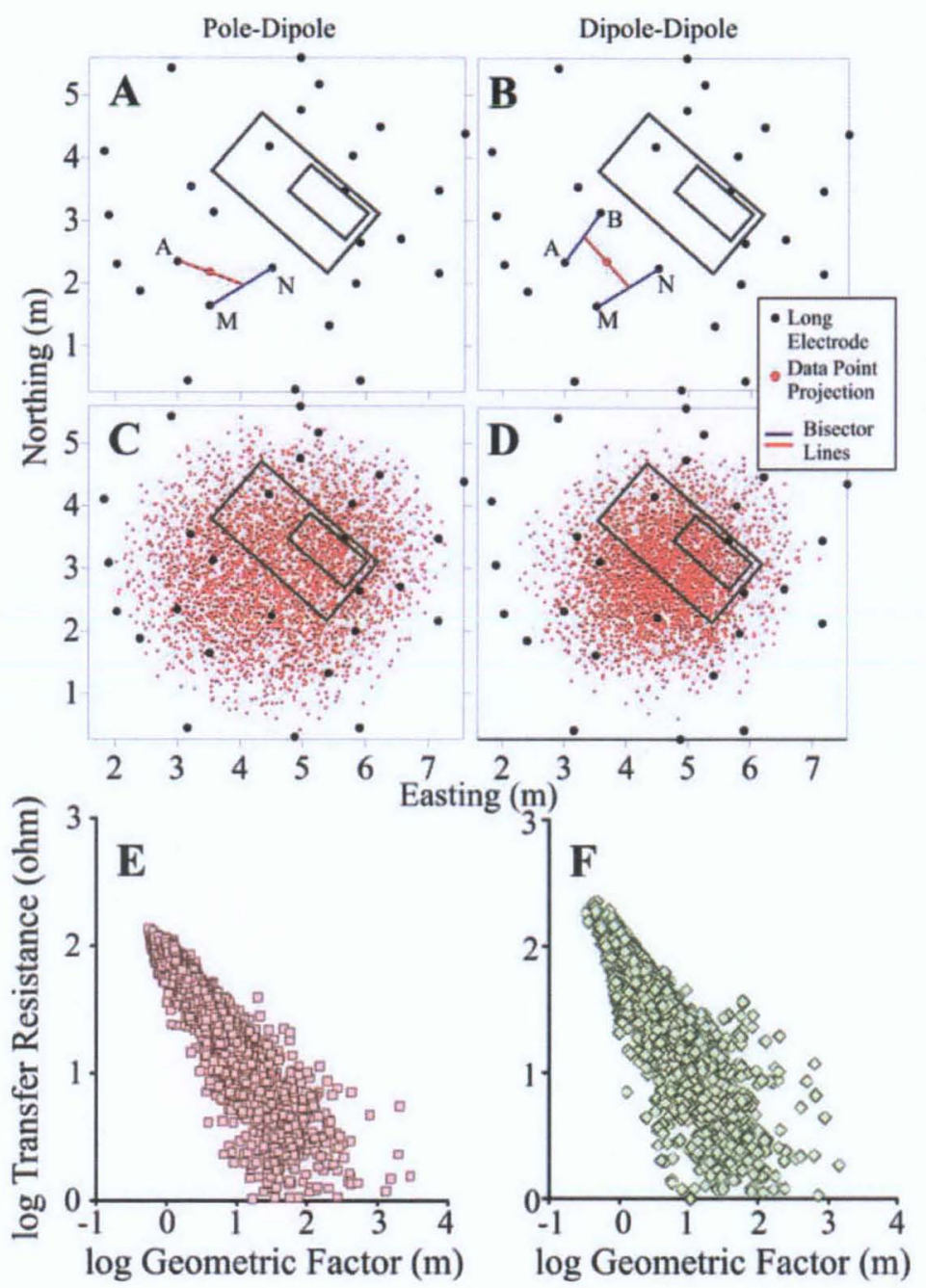

Figure 7. Electrical data statistics for the long electrode using pole-dipole (PD) and dipole-dipole (DD) arrays. A) Example calculation of data point projection using bisector lines for PD. B) Example calculation of data point projection using bisector lines for DD. C) Point cloud for PD. D) Point cloud for DD. E) Transfer resistance versus geometric factor for PD. F) Transfer resistance versus geometric factor for DD.

The inverse model results for the PD and DD arrays, using a consistent inverse model cell size of $0.3 \mathrm{~m}$, are shown in Figure 8. Data from only the top model layer at $0.1 \mathrm{~m}$ are presented in all images. A different color scale was developed for this figure, due to the range of resistivity values of the PD and DD array being broader than the PP array. However, a consistent model resolution color scale was retained for direct comparison to all previous models. The most remarkable aspect of the resistivity 
results for PD and DD is the placement of the low resistivity target to the east of the actual target in both examples despite generally higher model resolution values. The reasons for the offset in the target's location may be due to 1 ) the non-optimal sampling from electrode pairs, and 2) noise. Rucker et al. (2011) also showed a displaced reconstructed target in a model validation with long electrodes for conditions with high noise. When evaluating individual transmitter electrode pairs around the target, some pairs are represented reasonably well in the data as observed by the number of accompanying receiver electrode pair measurements, while others have fewer receiver measurements. Additionally, when observing transmitter and receiver electrode pairs using combinations that include the long electrode just to the northwest of the reconstructed target, generally a lower geometric factor is observed relative to other pairs where the resistivity is higher (e.g., at the actual target location). Then, when plotting transfer resistance data from subsets of transmitter well pairs, those with higher geometric factor have more data scatter and higher variability in the power fit function. Depending on transmitter well pair, the exponent for the power fit can range from -0.55 to -0.87 , with the higher exponent attributed to wells in the target and thus a higher resistivity.

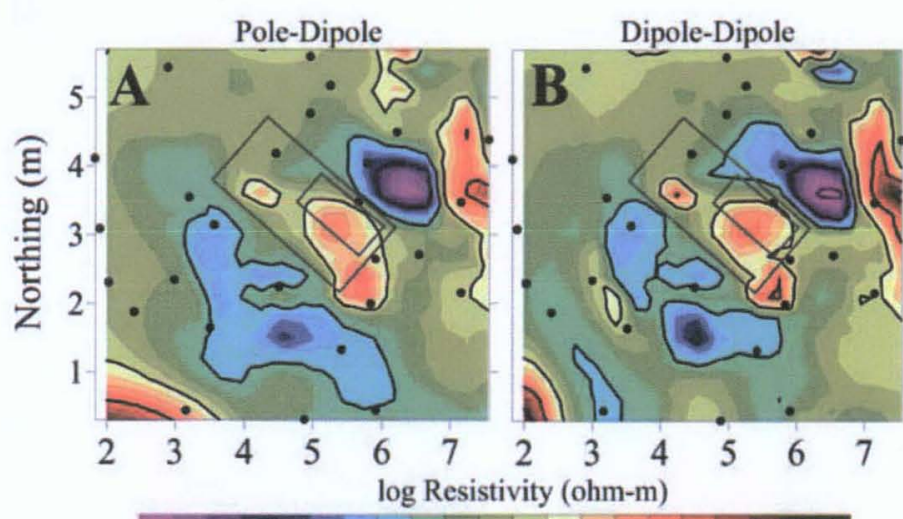

$\begin{array}{lllllllllll}2.2 & 2.35 & 2.5 & 2.65 & 2.8 & 2.95 & 3.1 & 3.25 & 3.4 & 3.55 & 3.7\end{array}$

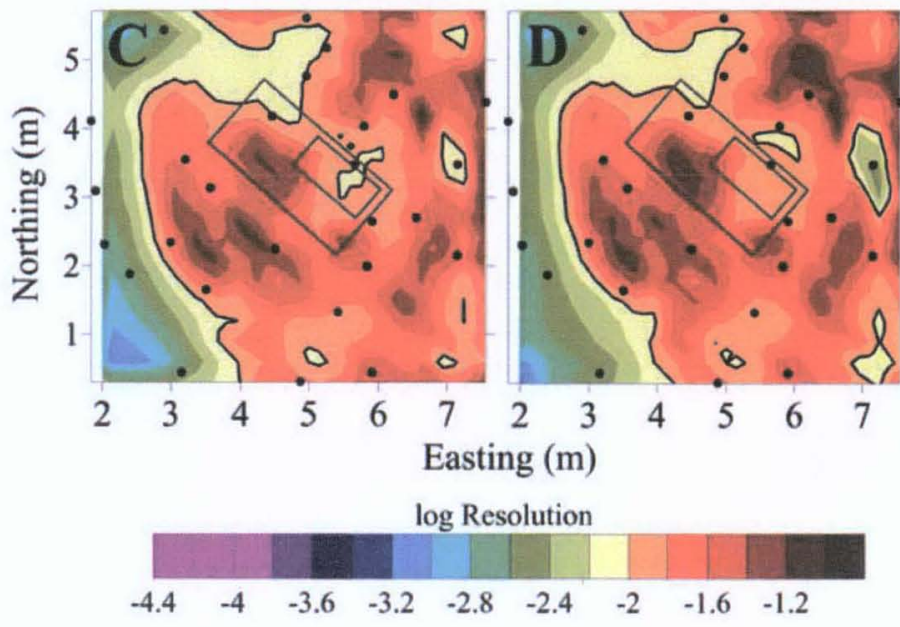

Figure 8. Inversion results for the LE-ERT for the PD and DD arrays. Feature legend for the contour plots are the same as Figure 4. A) Resistivity of the top model layer with cell size of $0.3 \mathrm{~m}$ for PD array. B) 
Resistivity of the top model layer with cell size of $0.3 \mathrm{~m}$ for DD array. C) Resolution of the top model layer for PD array. D) Resolution of the top model layer for DD array.

The model resolution plots of Figures $8 \mathrm{C}$ and $8 \mathrm{D}$ show much higher average and maximum values than that of the PP array. The maximum resolution for both PD and DD for the top layer of the model is 0.021 , compared to a value of 0.008 for the PP; the average model resolution values for PD, DD, and PP are $0.021,0.023$, and 0.0016 respectively. Despite the higher resolution, the PP model for longelectrode validation is superior in this example because the exhaustive combinations of transmitter and receiver electrode pairs are easier to obtain and the signal to noise ratio is significantly higher. The resistivity distribution for the PP array matched the actual amended soil target quite well. In contrast, the PD and DD arrays showed an offset target with a significantly higher number of other low resistivity features unrelated to the constructed plume. Despite these deficiencies, more research should be devoted to the PD and DD arrays for the LE-ERT method. Similar to the work of Stummer et al (2004), Wilkinson et al. (2006), and Loke et al. (2010), optimum sets of electrode transmitter and receiver pairs should be obtained through the evaluation of the model resolution matrix as well as the geometric factor. These pairs could then be ranked accordingly and the final number of measurement optimized to the temporal constraints of the project. In the interim, the PP array works well for locating a target, and the time to acquire an exhaustive dataset is very short. The temporal aspect to every project is important, especially when considering dynamic events such as a leak from a nuclear waste tank (Rucker et al., 2011a) or monitoring the secondary recovery of oil (Daily et al., 2004).

\section{Conclusions}

A pilot-scale validation experiment was conducted to test the ability of the long-electrode electrical resistivity tomography method to reconstruct a known target. The scale of the validation test was on the order of $1 / 17$ of a typical Hanford nuclear waste tank, where the LE-ERT method has been applied to image several waste plumes that have developed beneath the tanks from accidental releases (e.g., Rucker et al., 2010; 2011b). Amended soil, of known electrical resistivity, was packed into wooden forms between the depths of 0.6 and $0.9 \mathrm{~m}$ to mimic a conductive plume. The amended soil was backfilled with the native material. Several electrode types and acquisition strategies were tested, including: 1) point electrodes on the surface and buried within the domain using the pole-pole array, and 2) long electrodes arranged in a similar pattern as those around a Hanford tank using the pole-pole, pole-dipole, and dipole-dipole arrays. Finally, the resolution matrix was evaluated for each model to compare acquisition strategies and choice of model parameters on the model's ability to recreate the target.

When evaluating the fidelity of the target reconstruction, the point electrode method was shown to have the highest accuracy as long as depth electrodes were included. Even when the inverse model cell size was twice as large as the electrode separation, the target's location and depth were reproduced well. From a modeling perspective, the larger cell size actually created the highest model resolution values, with the lowest resolution observed from the model with no depth electrodes. Depth electrodes are important when surface electrodes are sparse, and arrays of depth electrodes buried in actual tank farm settings have proven to be a valuable means to evaluate historical leaks (Rucker et al., 2011b).

The results from the LE-ERT method using the pole-pole array were shown to be almost identical as the point electrode results in imaging the lateral extents of the plume. In contrast, the LE-ERT had a significantly lower number of electrodes and total measurements compared to the point electrodes. The drawback is the vertical position of the target is lost, as the current modeling algorithm forces most of the electrical current density in the upper portion of the model. Additionally, the model resolution 
values are generally lower for the LE-ERT method using the pole-pole array. Obviously, if there were a choice for survey design, a full spread of point electrodes on the surface and buried within the soil would be preferred. In some settings using point electrodes may not be an option due to administrative or physical limitations at the site and the LE-ERT method may be a suitable substitute for identifying targets.

The last two tests were conducted with the pole-dipole and dipole-dipole array using the long electrodes. The PD and DD arrays allowed a ten-fold increase in the number of measurements acquired compared to the PP array, yet only a fraction of an exhaustive dataset was acquired for either array. Generally, the PD and DD showed higher noise in the transfer resistance data as a function of geometric factor. Although a target was identified in both PD and DD models, the noise and small subset of data likely attributed to the poor performance in correctly positioning the reconstructed target at the known location. Remarkably, the PD and DD LE-ERT had significantly higher average model resolution values at the surface and deeper within the profile compared to any of the pole-pole acquisition strategies, with a factor of ten higher than the long electrode and a factor of eight higher than the point electrode polepole results. This suggests that the PD and DD may be a better imaging method for deep surveys where a limited numbers of buried electrodes are available, provided the measurement noise could be reduced and optimum electrode pairs could be identified. Until then, the PP array will suffice in identifying simple target locations and extents.

\section{References}

Adepelumi, A.A., A.A. Solanke, O.B. Sanusi and A.M. Shallangwa, 2006. Model tank electrical resistivity characterization of LNAPL migration in a clayey-sand formation. Environmental Geology 50, 1221-1233.

Alumbaugh, D. L., and G.A. Newman, 2000. Image appraisal for 2-D and 3-D electromagnetic inversion. Geophysics, 65, 1455-1467.

Baker, V.R., and R.C. Bunker, 1985. Cataclysmic late pleistocene flooding from glacial Lake Missoula: A review. Quaternary Science Review 4, 1-41.

Bergeron, M.P., M.P. Connelly, S.P. Reidel, 2010. Flow and Transport in the Natural System at Waste Management Area C, RPP-RPT-40688. Washington River Protection Solutions, LLC, Richland, WA.

Binley, A., S. Henry-Poulter, and B. Shaw, 1996. Examination of solute transport in an undisturbed soil column using electrical resistance tomography. Water Resource Research 32, 763-769.

Bjornstad, B.N., K.R. Fecht, C.J. Pluhar, 2001. Long History of Pre-Wisconsin, Ice Age Cataclysmic Floods: Evidence from Southeastern Washington State. The Journal of Geology 109, 695-713.

Bjornstad, B.N. and D.C. Lanigan, 2007. Geologic Descriptions for the Solid-Waste Low Level Burial Grounds, PNNL-16887. Pacific Northwest National Laboratory, Richland, WA.

Calendine, S., D.F. Rucker, J.B. Fink, M.T. Levitt, and J. Schofield, 2011. Automated Leak Detection of Buried Tanks using Geophysical Methods at the Hanford Nuclear Site. SAGEEP 2011, Annual meeting of the Environmental and Engineering Geophysical Society, Charleston, SC. April 10-14, 2011.

Cassiani, G., V. Bruno, A. Villa, N. Fusi, A.M. Binley, 2006. A saline trace test monitored via time-lapse surface electrical resistivity tomography. Journal of Applied Geophysics 59, 244-259. 
Chambers, J.E., M.H. Loke, R.D. Ogilvy, and P.I. Meldrum, 2004. Noninvasive monitoring of DNAPL migration through a saturated porous medium using electrical impedance tomography. Journal of Contaminant Hydrology 68, 1-22.

Chambers, J.E., Wilkinson, P.B., Wealthall, G.P., Loke, M.H., Dearden, R., Wilson, R., Ogilvy, R.D., 2010. Hydrogeophysical Imaging of Deposit Heterogeneity and Groundwater Chemistry Changes during DNAPL Source Zone Bioremediation. Journal of Contaminant Hydrology 118, 43-61.

Daily, W., A. Ramirez, R. Newmark, and K. Masica, 2004. Low-cost reservoir tomographs of electrical resistivity. Leading Edge 23, 472-480.

Damasceno, V.M., D. Fratta, and P.J. Bosscher, 2009. Development and validation of a low-cost electrical resistivity tomographer for soil process monitoring. Canadian Geotechnical Journal 46, 842854.

Day-Lewis, F.D., K. Singha, and A.M. Binley,2005. Applying petrophysical models to radar travel time and electrical resistivity tomograms: resolution-dependent limitations. Journal of Geophysical Research 110, B08206

Deiana, R., G. Cassiani, A. Kemna, A. Villa, V. Bruno, and A. Bagliani, 2007. An experiment of noninvasive characterization of the vadose zone via water injection and cross-hole time-lapse geophysical monitoring. Near Surface Geophysics 5, 183-194.

Dey, A. and H.F. Morrison, 1979. Resistivity modeling for arbitrarily shaped three-dimensional shaped structures. Geophysics 44, 753-780.

Gee, G. W., M. Oostrom, M.D. Freshley, M.L. Rockhold, and J.M. Zachara, 2007. Hanford site vadose zone studies: An overview. Vadose Zone Journal 6, 899.

Glaser, D.R., J.B., Fink, M.T. Levitt, and D.F. Rucker, 2008. A Summary of Recent Geophysical Investigations at the Department of Energy Hanford Nuclear Facility, Abstract \#B-04. Americal Geophysical Union, Chapman Conference on Biogeophysics, Portland, ME, 12-16 Oct.

Hayley, K., L.R. Bentley, and M. Gharibi, 2009. Time-lapse electrical resistivity monitoring of saltaffected soil and groundwater. Water Resources Research 45, W07425.

Kemna, A., B. Kulessa, and H. Vereecken, 2002. Imaging and characterisation of subsurface solute transport using electrical resistivity tomography (ERT) and equivalent transport models. Journal of Hydrology 267, 125-146.

Knepp, A.J., 2002. Field Investigation Report for Waste Management Area B-BY-BX, RPP-10098. CH2M Hill Hanford Group, Inc., Richland, WA.

Koestel, J., R. Kasteel, A. Kemna, O. Esser, M. Javaux, A. Binley and H. Vereecken, 2009. Imaging Brilliant Blue Stained Soil by Means of Electrical Resistivity Tomography. Vadose Zone Journal 8, 963-975. 
$\mathrm{Li}, \mathrm{Y}$. and D. Oldenburg, 1994. Inversion of 3-D DC resistivity data using an approximate inverse mapping. Geophysical Journal International 116, 527-537.

de Lima, O.A.L, H.K. Sato and M.J. Porsani, 1995. Imaging industrial contaminant plumes with resistivity techniques. Journal of Applied Geophysics 34, 93-108.

Loke, M.H., I. Acworth and T. Dahlin, 2003. A comparison of smooth and blocky inversion methods in 2D electrical imaging surveys. Exploration Geophysics 34, 182-187.

Loke, M.H., P.B. Wilkinson, and J.C. Chambers, 2010. Fast computation of optimized electrode arrays for 2D resistivity surveys. Computers \& Geosciences $36,1414-1426$.

Looms, M.C., K.H. Jensen, A. Binley, and L. Nielsen, 2008. Monitoring Unsaturated Flow and Transport Using Cross-Borehole Geophysical Methods. Vadose Zone Journal 7, 227-237.

Meju, M.A., and M. Montague, 1995. Basis for a flexible low-cost automated resistivity data acquisition and analysis system. Computers \& Geosciences 21, 993-999.

Monego, M., G. Cassiani, R. Deiana, M. Putti, G. Passadore, and L. Altissimo, 2010. A tracer test in a shallow heterogeneous aquifer monitored via time-lapse surface electrical resistivity tomography. Geophysics 75, WA61-WA73.

Oldenborger, G.A., M.D. Knoll, P.S. Routh, and D.J. LaBrecque, 2007. Time-lapse ERT monitoring of an injection/withdrawal experiment in a shallow unconfined aquifer. Geophysics 72, F177-F187.

Park, S.P. and G.P. Van, 1991. Inversion of pole-pole data for 3-D resistivity structure beneath arrays of electrodes. Geophysics 56, 951-960.

Ramirez, A.L., R.L. Newmark, and W.D. Daily, 2003. Monitoring carbon dioxide floods using electrical resistance tomography (ERT): Sensitivity studies. Journal of Environmental and Engineering Geophysics 8, 187-198.

Reidel, S.P., K.A. Lindsey, and K.R. Fecht, 1992. Field Trip Guide to the Hanford Site, WHC-MR-0391. Westinghouse Hanford Company, Richland, WA.

Rucker, D.F., M.T. Levitt, and W.J. Greenwood, 2009. Three-dimensional electrical resistivity model of a nuclear waste disposal site. Journal of Applied Geophysics 69:150-164.

Rucker, D.F., M.H. Loke, G.E. Noonan, and M.T. Levitt, 2010. Electrical resistivity characterization of an industrial site using long electrodes. Geophysics 75, WA95-WA104.

Rucker, D.F., J.B. Fink, and M.H. Loke, 2011a. Environmental monitoring of leaks using time lapsed long electrode electrical resistivity. Journal of Applied Geophysics 74(4):242-254.

Rucker, D.F., D.A. Myers, B.D. Cubbage, M.T. Levitt, G.E. Noonan, M. McNeill, C. Henderson, and R.W. Lober, 2011b. Environmental Monitoring and Assessment (in review). 
Sasaki, Y., 1992. Resolution of resistivity tomography inferred from numerical simulation. Geophysical Prospecting 40, 453-463.

Seidel, K. and G. Lange, 2007. Direct current resistivity methods. Environmental Geology 4, 205-237.

Singha, K. and Gorelick, S.M., 2005. Saline tracer visualized with electrical resistivity tomography: field scale spatial moment analysis. Water Resources Research 41, W05023

Slater, L., M.D. Zaidman, A.M. Binley, and L.J. West, 1997. Electrical Imaging of Saline Tracer Migration for the Investigation of Unsaturated Zone Transport Mechanisms. Hydrology and Earth System Sciences $1,291-302$.

Slater, L., A.M. Binley, W. Daily, and R. Johnson, 2000. Cross-hole electrical imaging of a controlled saline tracer injection. Journal of Applied Geophysics 44, 85-102.

Slater, L., A. Binley, R. Versteeg, G. Cassiani, R. Birken, and S. Sandberg, 2002. A 3D ERT study of solute transport in a large experimental tank. Journal of Applied Geophysics 49, 211-229.

Stummer, P., H. Maurer, and A. Green,2004. Experimental design: electrical resistivity data sets that provide optimum subsurface information. Geophysics 69,120-129.

Telford, W., Geldart, L., Sheriff, R., 1990. Applied Geophysics. Cambridge Univ Press, Cambridge.

Udphuay, S., T. Gunther, M.E. Everett, R.R. Warden, and J.-L. Briaud, 2011. Three-dimensional resistivity tomography in extreme coastal terrain amidst dense cultural signals: application to cliff stability assessment at the historic D-Day site. Geophysical Journal International 185, 201-220.

White, P.A., 1988. Measurement of Ground-Water Parameters Using Salt-Water Injection and Surface Resistivity. Groundwater 26, 179-186.

Wilkinson, P.B., P.I. Meldrum, J.C. Chambers, O. Kuras, and R.D. Ogilvy, 2006. Improved strategies for the automatic selection of optimized sets of electrical resistivity tomography measurement configurations. Geophysical Journal International 167,1119-1126.

Zhu, T., R. Feng, 2011. Resistivity tomography with a vertical line current source and its applications to the evaluation of residual oil saturation. Journal of Applied Geophysics 73, 155-163. 